\title{
OSTEOTOMY FOR OSTEOARTHRITIS OF THE HIP
}

\author{
A SURVIVORSHIP ANALYSIS
}

R. WERNERS, B. VINCENT, C. BULSTRODE

From Oxford University and the Nuffield Orthopaedic Centre

\begin{abstract}
We have reviewed 368 osteotomies carried out for osteoarthritis of the hip at the Nuffield Orthopaedic Centre. Survivorship analysis showed that 10 years after osteotomy $47 \%$ had required no further surgery, and even after 20 years $23 \%$ had still not had a hip replacement.

Hips with moderate arthritic change showed significantly better results than those with more severe degeneration. Osteotomies with varus angulation as well as medial displacement showed longer survival.
\end{abstract}

In 1935 McMurray described an oblique medial displacement intertrochanteric osteotomy for osteoarthritis of the hip; since then, opinion on its value has varied widely (Duthie and Howe 1963; Morscher 1971; Watillon, Hoet and Maquet 1978; Collert and Gillström 1979; Schneider 1979; Weisl 1980; Mogensen, Zoëga and Marinko 1980; Miegel and Harris 1984). Total hip replacement was preferred to osteotomy in many units even before the long-term results of osteotomy had been fully evaluated.

Poss (1984) has provided a comprehensive survey of the current role of osteotomy in the treatment of osteoarthritis of the hip and Dorey and Amstutz (1989) have shown that survivorship analysis is valid in retrospective studies where some patients cannot be traced.

We report the natural history of 368 osteotomies performed at the Nuffield Orthopaedic Centre, Oxford, measuring their long-term value simply in terms of time to total hip replacement.

\section{PATIENTS AND METHODS}

From 1960 to 1985 , a total of 680 patients had a medial displacement femoral osteotomy for osteoarthritis of the

R. Werners, MD, Nuffield Scholar

Department of Orthopaedic Surgery, University of Kiel, Michaelisstr.

1, D-2300 Kiel 1, West Germany.

B. Vincent, MD, Girdlestone Scholar,

Department of Orthopaedic Surgery, University Louvain, Av. Hypocrate, 1200 Brussels, Belgium.

C. Bulstrode, MCh, FRCS, Clinical Reader

Nuffield Department of Orthopaedic Surgery, University of Oxford,

Nuffield Orthopaedic Centre, Headington, Oxford OX3 7LD, England.

Correspondence should be sent to Mr C. Bulstrode.

(C) 1990 British Editorial Society of Bone and Joint Surgery

0301-620X/90/6020 $\$ 2.00$

J Bone Joint Surg [Br] 1990; 72-B: 1010-3.

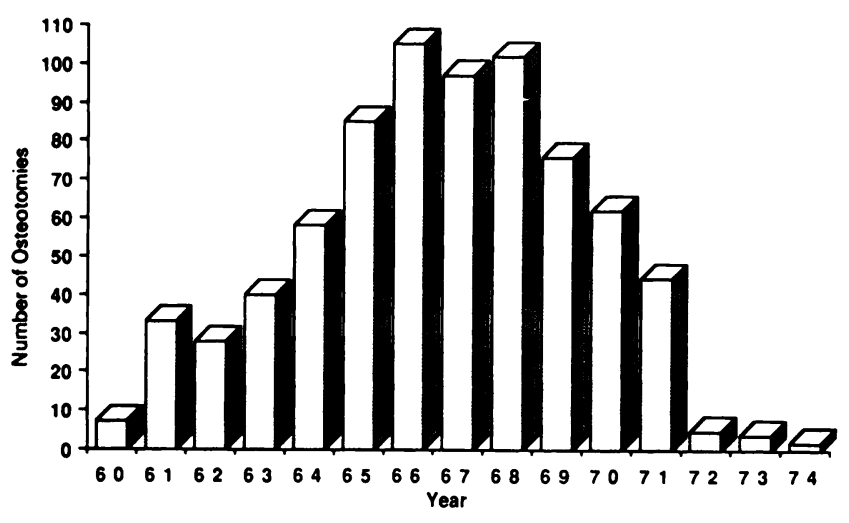

Fig. 1

Number of femoral osteotomies for osteoarthritis of the hip performed each year at the Nuffield Orthopaedic Centre from 1960 to 1974.

hip at the Nuffield Orthopaedic Centre. Of these, 75 had bilateral operations, giving a total of 755 osteotomies (Fig. 1). Only six osteotomies were performed later than 1974. Records showed that 239 of these hips had subsequently been converted to a total hip replacement at the NOC. The fate of the other 516 hips was investigated. General practitioners were asked whether the patients were still alive and when, if ever, the osteotomy had been converted to a total hip replacement. Eventually we had full information on 368 osteotomies. The pre-operative radiographs were available for 152 hips; for these the type and severity of the arthritis of the hip was assessed, using five groups (Wroblewski and Charnley 1982).

We then used survivorship curves to analyse the results of the osteotomies (Kaplan and Meier 1958), and tested for significant differences between various groups using the log rank test (Mantel and Haenszel 1959) with significance set at $\mathrm{p}<0.05$. 


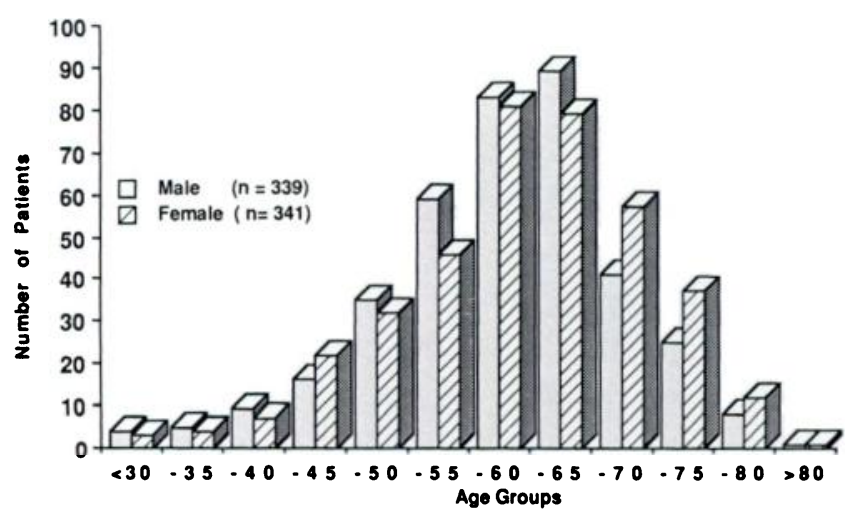

Fig. 2

Age and sex distribution; 680 patients having femoral osteotomies for osteoarthritis of the hip.

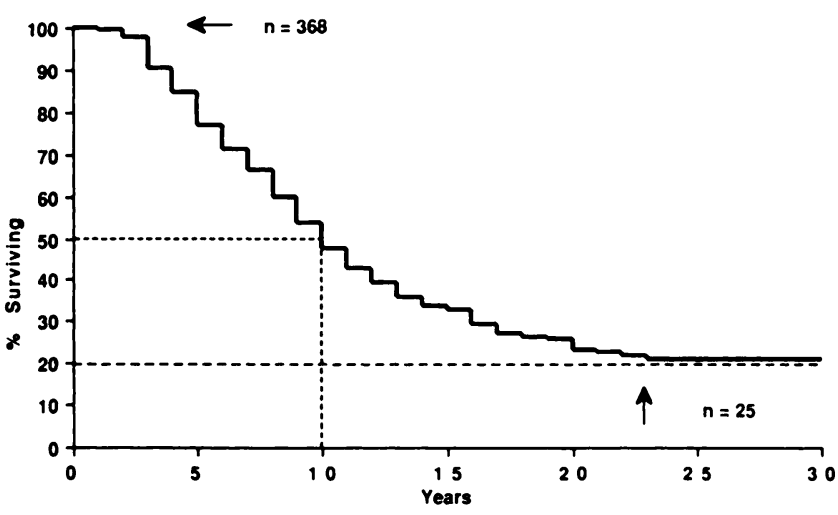

Fig. 3

Survivorship curve for 368 osteotomies, taking revision to total hip replacement as the end-point (see Table II).

\section{RESULTS}

The mean age of the 680 patients was 59 years (range 16 to 86 , Fig. 2). Of the 755 osteotomies, only 32 had complications $(4.2 \%)$, which are listed in Table I.

Full follow-up records, until the death of the patient or the present day, were available for 368 osteotomies: 266 had had total hip replacement $(72 \%)$, and $102(28 \%)$ had required no further surgery. At five years after osteotomy, $33 \%$ had been converted and at 10 years $53 \%$ had had a total hip replacement. At 20 years (the longest period for which the data remains reliable, $\mathrm{n}=56) 23 \%$ of the osteotomies were still unconverted. The $50 \%$ survival for all 368 osteotomies was almost exactly 10 years (Table II, Fig. 3). We found no difference in

Table II. Survivorship of 368 osteotomies for osteoarthritis of the hip, taking failure as revision to total hip arthroplasty. Similar tables were drawn up for each of the subgroups shown in Figures 4 to 8

\begin{tabular}{lllll}
\hline $\begin{array}{l}\text { Interval since } \\
\text { operation (yr) }\end{array}$ & $\begin{array}{l}\text { Number at start } \\
\text { of interval }\end{array}$ & $\begin{array}{l}\text { Total hip } \\
\text { replacement }\end{array}$ & $\begin{array}{l}\text { Number } \\
\text { withdrawn }\end{array}$ & $\begin{array}{l}\text { Cumulative } \\
\text { survivors at start } \\
\text { of interval (\%) }\end{array}$ \\
\hline 0 to 1 & 368 & 1 & 3 & 100.0 \\
1 to 2 & 364 & 6 & 2 & 99.7 \\
2 to 3 & 356 & 28 & 2 & 98.0 \\
3 to 4 & 326 & 20 & 0 & 90.2 \\
4 to 5 & 306 & 28 & 2 & 84.7 \\
5 to 6 & 276 & 21 & 1 & 76.9 \\
6 to 7 & 254 & 17 & 2 & 71.0 \\
7 to 8 & 235 & 22 & 4 & 66.2 \\
8 to 9 & 209 & 21 & 3 & 59.9 \\
9 to 10 & 185 & 22 & 1 & 53.8 \\
10 to 11 & 162 & 15 & 1 & 47.4 \\
11 to 12 & 146 & 12 & 0 & 42.9 \\
12 to 13 & 134 & 11 & 5 & 39.4 \\
13 to 14 & 118 & 8 & 0 & 36.0 \\
14 to 15 & 110 & 3 & 1 & 33.6 \\
15 to 16 & 106 & 11 & 2 & 32.7 \\
16 to 17 & 93 & 7 & 3 & 29.2 \\
17 to 18 & 83 & 2 & 1 & 26.9 \\
18 to 19 & 80 & 1 & 7 & 26.3 \\
19 to 20 & 72 & 7 & 9 & 25.9 \\
20 to 21 & 56 & 1 & 9 & 23.0 \\
21 to 22 & 46 & 1 & 8 & 22.4 \\
23 to 24 & 37 & 1 & 11 & 21.9 \\
24 to 25 & 25 & 0 & 10 & 21.0 \\
25 to 26 & 15 & 0 & 7 & \\
26 to 27 & 8 & 0 & 3 & \\
27 to 28 & 5 & 0 & 1 & \\
28 to 29 & 4 & 0 & 3 & 1 \\
29 to 30 & 3 & 0 & & \\
\hline & & & & \\
\hline
\end{tabular}


Table III. Classification of osteoarthritis on pre-operative radiographs (Wroblewski 1982)

\begin{tabular}{llll}
\hline Type & Number & Criteria & 50\% survival (yr) \\
\hline I moderate & 56 & $\begin{array}{l}\text { Joint space narrow, or absent; moderate osteophytes; } \\
\text { femoral head spherical or only slightly flattened }\end{array}$ & 12 \\
II severe & 50 & $\begin{array}{l}\text { Osteophytes medially with lateral displacement; femoral } \\
\text { head appreciably flattened; Shenton's line intact }\end{array}$ & 9 \\
III extreme & 19 & $\begin{array}{l}\text { Secondary subluxation; broken Shenton's line; gross loss of } \\
\text { head substance }\end{array}$ & 6 \\
IV medial & 19 & $\begin{array}{l}\text { Good or narrow joint space superiorly but absent medially; } \\
\text { no bulging of pelvis medially }\end{array}$ & 8 \\
V concentric & 8 & $\begin{array}{l}\text { Concentric loss or narrowing of joint space; femoral head } \\
\text { spherical; no destruction; minimal osteophytes }\end{array}$ & Too few \\
\hline
\end{tabular}

survival between men and women (Fig. 4) or between different age groups (Fig. 5). By diagnosis on preoperative radiographs, using the criteria shown in Table III, we found that the $50 \%$ survival of type 1 (moderate) arthritis was 12 years as against six to nine years for the other groups (Table III, Fig. 6).

Experienced surgeons, who had performed more than 20 osteotomies, had significantly better results than those who had done less than 20 osteotomies at the Nuffield Orthopaedic Centre (Fig. 7). Although some consultants had strong preferences for certain types of osteotomy, the patients in each group did not differ significantly in terms of age, gender, or severity of arthritis.

Most osteotomies showed medial displacement with no angulation (McMurray 1935) but 62 also had some varus angulation (Pauwels 1950 ). The $50 \%$ survival was 10 years for those with simple medial displacement as against 13 years with varus as well (Fig. 8 ). This difference is statistically significant.

\section{DISCUSSION}

From 1970 to 1980 there was a change from femoral osteotomy to total hip replacement in the treatment of osteoarthritis of the hip at Oxford. This transition has allowed us to compare the longevity of each management, using the need for revision hip replacement as the common end-point. Our results are in line with those previously reported: Schneider (1979) had $50 \%$ good or fair results after 12 to 15 years; Weisl (1980) recorded that two-thirds had pain relief for at least five years but that only one-quarter had lasting good results; Miegel and Harris (1984) reported that $51 \%$ of 73 cases had required no further surgery after 10 years.

In clear contra-distinction to total hip replacements (Johnsson, Thorngren and Persson 1988), we found that the survival of osteotomies did not alter with age at operation. The success of osteotomy in the young male patient is close to that found for primary total hip replacement in this age group (Dorr, Takei and Conaty 1983) and the great advantage of the osteotomy is the

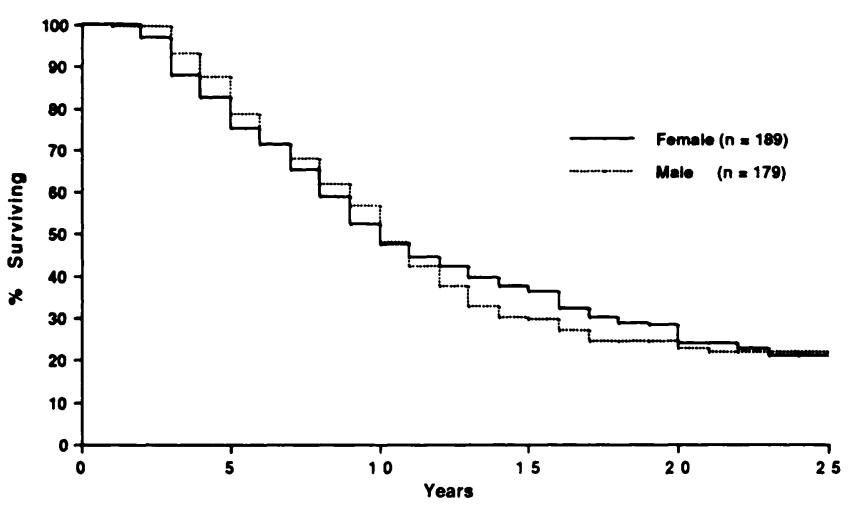

Fig. 4

Survival curves for osteotomies in male and female patients.

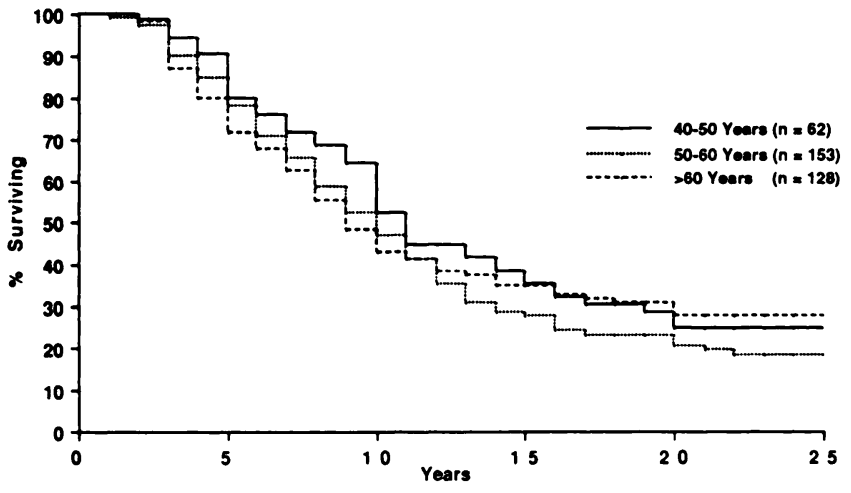

Fig. 5

Survival curves for osteotomies in three age groups of patients.

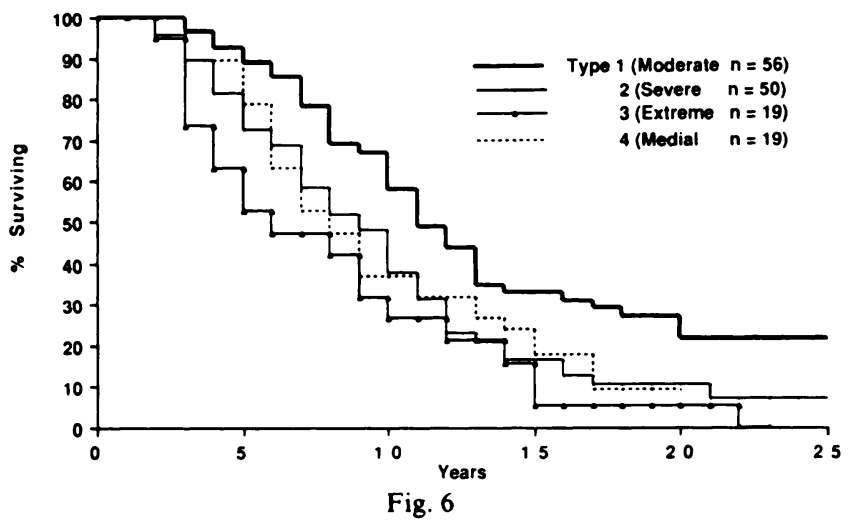

Survival curves for osteotomies in four types of osteoarthritis (see Table III). 


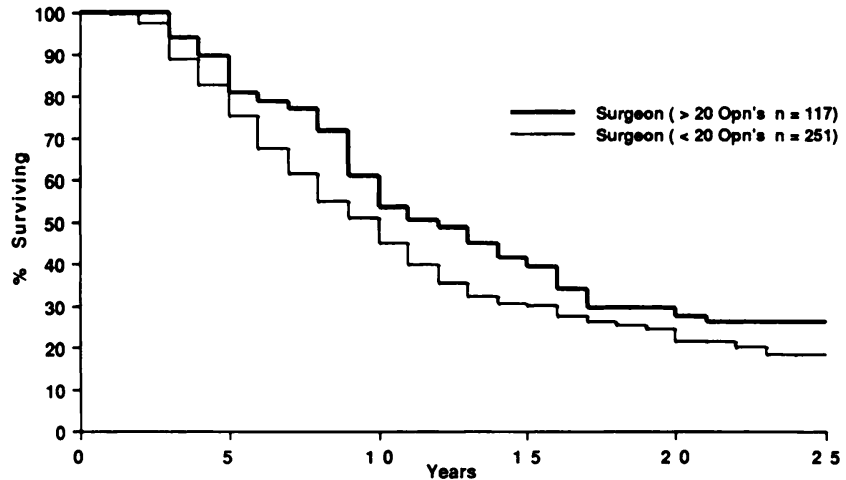

Fig. 7

Survival curves for osteotomies performed by experienced and by trainee surgeons.

appreciable delay in the need for such replacement. In elderly patients hip replacement gave much better survival.

Hips showing moderate arthritis (type I) survived significantly longer than those in any other group. Medial displacement with some varus angulation gave better results than simple medial displacement. This was not the result of selection for different types of arthritis nor was it related to the skill of the surgeon performing the varus osteotomy.

We found no differences in the survivorship curves for osteotomies performed by different consultant surgeons, but those trainee surgeons who had performed less than 20 osteotomies achieved significantly shorter survivals than their more experienced colleagues, suggesting that the operation requires experience before optimum results can be obtained.

There has been justifiable criticism of the methods used in retrospective studies of hip replacement surgery (Gartland 1988; Gross 1988), for this reason we confined

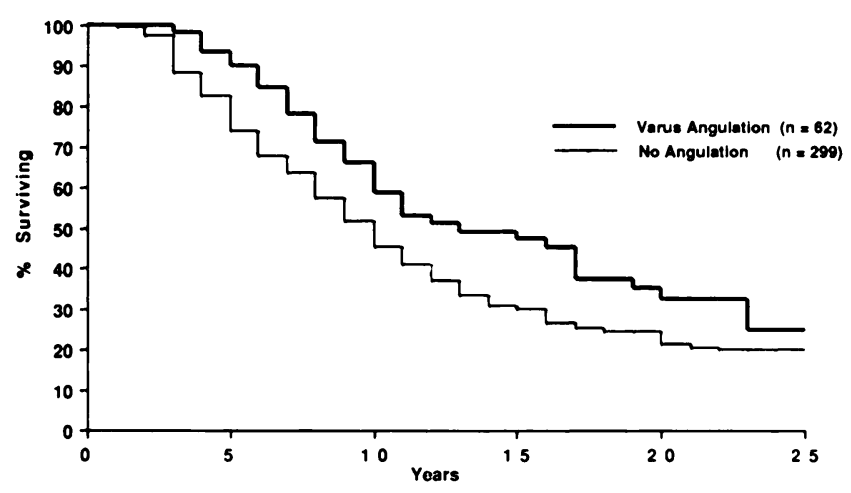

Fig. 8

Survival curves for osteotomies with and without varus angulation.

our study to a survivorship analysis with the single fixed end-point of conversion to total hip replacement.

Conclusions. Our study has shown that there may still be a place for osteotomy in the treatment of primary osteoarthritis of the hip in the younger patient. In this group the survival of an osteotomy is as good as in older patients and useful postponement of total hip replacement can be obtained. The osteotomy is probably better performed early, when the hip shows only moderate radiological change. The best results were for varus and medial displacement osteotomies performed by experienced surgeons. The patient can be offered a $50 \%$ chance that revision to a total hip replacement can be postponed for 10 years and a $20 \%$ chance of delay for more than 25 years.

We thank Professor R. B. Duthie for supporting this project and all the past and present consultants of the Nuffield Orthopaedic Centre who allowed their patients to be studied.

No benefits in any form have been received or will be received from a commercial party related directly or indirectly to the subject of this article.

\section{REFERENCES}

Collert S, Gillström P. Osteotomy in osteoarthritis of the hip: a prospective study. Acta Orthop Scand 1979; 50:555-61.

Dorey F, Amstutz HC. The validity of survivorship analysis in total joint arthroplasty. J Bone Joint Surg [Am] 1989; 71-A:544-8.

Dorr LD, Takei GK, Conaty JP. Total hip arthroplasties in patients less than 45 years old. J Bone Joint Surg [ Am] 1983; 65-A :474-9.

Duthie RB, Howe WW. Displacement osteotomy for arthritis of the hip. Clin Orthop 1963; $31: 65-72$.

Gartland JJ. Orthopaedic clinical research : deficiencies in experimental design and determinations of outcome. J Bone Joint Surg [Am] $1988 ; 70-A: 1357-64$.

Gross M. A critique of the methodologies used in clinical studies of hipjoint arthroplasty published in the English-language orthopaedic literature. J Bone Joint Surg [ Am] 1988; 70-A:1364-71.

Johnsson R, Thorngren K-G, Persson BM. Revision of total hip replacement for primary osteoarthritis. $J$ Bone Joint Surg [Br] 1988; 70-B:56-62.

Kaplan EL, Meier P. Nonparametric estimation from incomplete observations. J Am Stat Assoc 1958; 53:457-81.

McMurray TP. Osteo-arthritis of the hip joint. Br J Surg 1935; 22: 716-27.

Mantel N, Haenszel W. Statistical aspects of the analysis of data from retrospective studies of disease. Natl Cancer Inst 1959; 22:719-48.
Miegel RE, Harris WH. Medial-displacement intertrochanteric osteotomy in the treatment of osteoarthritis of the hip: a longterm follow-up study. J Bone Joint Surg [Am] 1984; 66-A : 878-87.

Mogensen BA, Zoëga H, Marinko P. Late results of intertrochanteric osteotomy for advanced osteoarthritis of the hip. Acta Orthop Scand 1980; $51: 85-90$.

Morscher E. Multizentrische Nachuntersuchung von 2251 intertrochanteren Osteotomien bei Coxarthrose. In: Morscher E, ed. Die intertrochantere Osteotomie bei Coxarthrose. Bern, etc: Verlag Hans Huber, 1971 :9-22.

Poss R. Current concepts review. The role of osteotomy in the treatment of osteoarthritis of the hip. J Bone Joint Surg [Am] 1984; 66A : 144-51.

Pauwels F. Über eine kausale Behandlung der Coxa valga luxans. $Z$ Orthop 1950; 79:305-15.

Schneider R. 12-15 Jahres-Resultate nach intertrochanterer Osteotomie bei Coxarthrose. Orthopäde 1979; 8:79-82.

Watillon M, Hoet F, Maquet P. Analyse de 804 cas d'ostéotomie. Acta Orthop Belg 1978; 44:248-79.

Weisl H. Intertrochanteric osteotomy for osteoarthritis: a long term follow-up. J Bone Joint Surg [Br] 1980; 62-B:37-42.

Wroblewski BM, Charnley J. Radiographic morphology of the osteoarthritic hip. J Bone Joint Surg [Br] 1982; 64-B:568-9. 